\title{
Causes and Effect of Job Stress and Coping on Performance and Psychological Well-being among the Agricultural Research Sector Employees: An Empirical Study Using Multinomial Logistic Regression Approach
}

\author{
${ }^{* 1}$ KDV Prasad, ${ }^{2}$ Rajesh Vaidya \\ ${ }^{* 1}$ International Crops Research Institute for the Semi-Arid Tropics (ICRISAT) \\ ${ }^{2}$ Assistant Professor, Department of Management Technology, Shri Ramdeobaba College of Engineering and \\ Management, RamdeoTekdi, Gittikhadan, Katol Road, Nagpur 444013 (Maharashtra State), India \\ Email:k.d.prasad@cgiar.org,rwvaidya@gmail.com
}

Received: $20^{\text {th }}$ September 2018, Accepted: $11^{\text {th }}$ October 2018, Published: $31^{\text {st }}$ October 2018

\begin{abstract}
This manuscript reports the results of our study to assess the influence of stress due to job, strategies adopted for coping the stress, their association, and effect on performance and psychological well-being of agricultural research sector (ARS) employees. A survey of 700 staff working in the ARS in Hyderabad Metro, consisting of 360 women and 340 men were carried out. The 14 independent job stress components, harassment, role ambiguity, psychological factors, peer support, workload, co-workers, role conflict, career, physiological factors, behavioral factors, job control and social support, strategies of coping both the approach \& avoidance strategies on dependent factors Performance and Psychological well-being of the agricultural research sector employees were estimated. The Cronbach's alpha value for the whole sample is 0.87 , and C-alpha values for the job stress components and outcome factors performance and psychological well-being ranged between $0.70-0.81$. The odds ratios (ORs) were measured to calculate the level of relation of job stress, coping methods, relationship with performance and psychological well-being of ARS staff. The age and gender differences were also studied.
\end{abstract}

Keywords

Job Stress, Agricultural Research Sector (ARS), Psychological Well-being, Coping, Gender

\section{Introduction}

The job stress or employment stress, a silent killer is extensively accepted problem by the social scientists, health specialists and all organizations including industry, research, information technology, IT enabled services. Job stress poses significant effect on well-being of an employee at personal level which leads to, low efficiency, disinterest to work, no keenness to learn new things and develop new avenues and thus the effect on performance of the employees (Cooper and Marshal, 1978).

Hans Selye (1956) an Endocrinologist from Austria first presented the idea of stress in the area of life sciences. The word stress has several meanings and defined differently as per the related subjects - stress defined as external energy or force in machine engineering (Pestonjee 1999). Researchers in early days has difficult and "stressful" time as the concept or word was entered into the vernacular during 1970s. The researchers, psychologists, health professionals have their own definition for the term "stress". Stress is a demanding or threating situation placed on individual (Kahn et. a.1964). The job stress viewed as, that a nature of the job that hurt individual resulting a mismatch between the abilities of a person, and requirements for carrying out the job (French and Caplan, 1970). Hans Selye (1976) defined it as "unspecific response of the body to any demand for change". The stress is a discomfort causing threat. Selye subsequently created a new concept, stressor, and stress is a reaction of an individual to a stressor. Stress is a "physical, mental, or emotional strain or tension".

\section{Review of Literature}

Supran Kumar Sharma, Jyoti Sharma, and Arti Devi (2012) carried out a multinomial logit analysis using a sample of 550 employees for role stress in commercial banks of Jammu and Kashmir State of India. A statistically significant differences were observed in log likelihood ratios of the factors indicating the influence of these factors in causing role stress.

Oluwole A. Odetunmibi M, (2017) investigated the influence of doctors stress in Nigerian hospitals using logistic regression method. The resulted indicated that the working hours and attending the number of patients are the main factors for doctors stress. Fourteen variables entered in the model, however, not all the variables are predicted the doctors stress.

Suryanwanshi et. al. 2015, used the nominal dependent variables and modelled these variables, using MLR and likelihood odd ratios of the outcomes are measured, as linear combination of the predictor variables. Several studies were carried using MLR model to predict the outcome variable stress from job, coping schemes, and its effect on performance physiological well-being and reported that stress not only effects the performance, also the 
psychological well-being of the employees (Sateeshkumar and Madhu, 2012; Stephen, 2014; MasoudLotfizadeh 2014).

Psychological well-being of employees is very important aspect of the working class. Psychological well-being is a measure, to identify the progress of any cohort of development, and it is used by the policymakers in developing and developed countries for the further improvement to assess the health of an employee. Ryff (1989) scale a 6dimension, 42 item scale was modified to suit the study and used to measure the psychological well-being of the staff (Figure 2). The research also witnessed the supporting system in relate to work engagement (Burns, 2016).

\section{Hypotheses}

$\mathbf{H}_{01}$ : Performance and psychological well-being of ARS Employees are not related to Job stress and coping

$\mathbf{H}_{11}$ :Performance and psychological well-being of ARS Employees are related to Job stress and coping

$\mathbf{H}_{\mathbf{0 2}}$ : The age and gender differences are not statistically significant with psychological well-being of ARS Employees

$\mathbf{H}_{12}$ :The age and gender differences are statistically significant with psychological well-being of ARS Employees

\section{Research Methodology}

Research Framework: The study adopted the research framework based on Seyle (1980), Prasad KDV et al. (2015 and, 2018, 2016). The 14 independent job stress components and two dependent factors the agricultural research sector employees were measured (Figure 1).

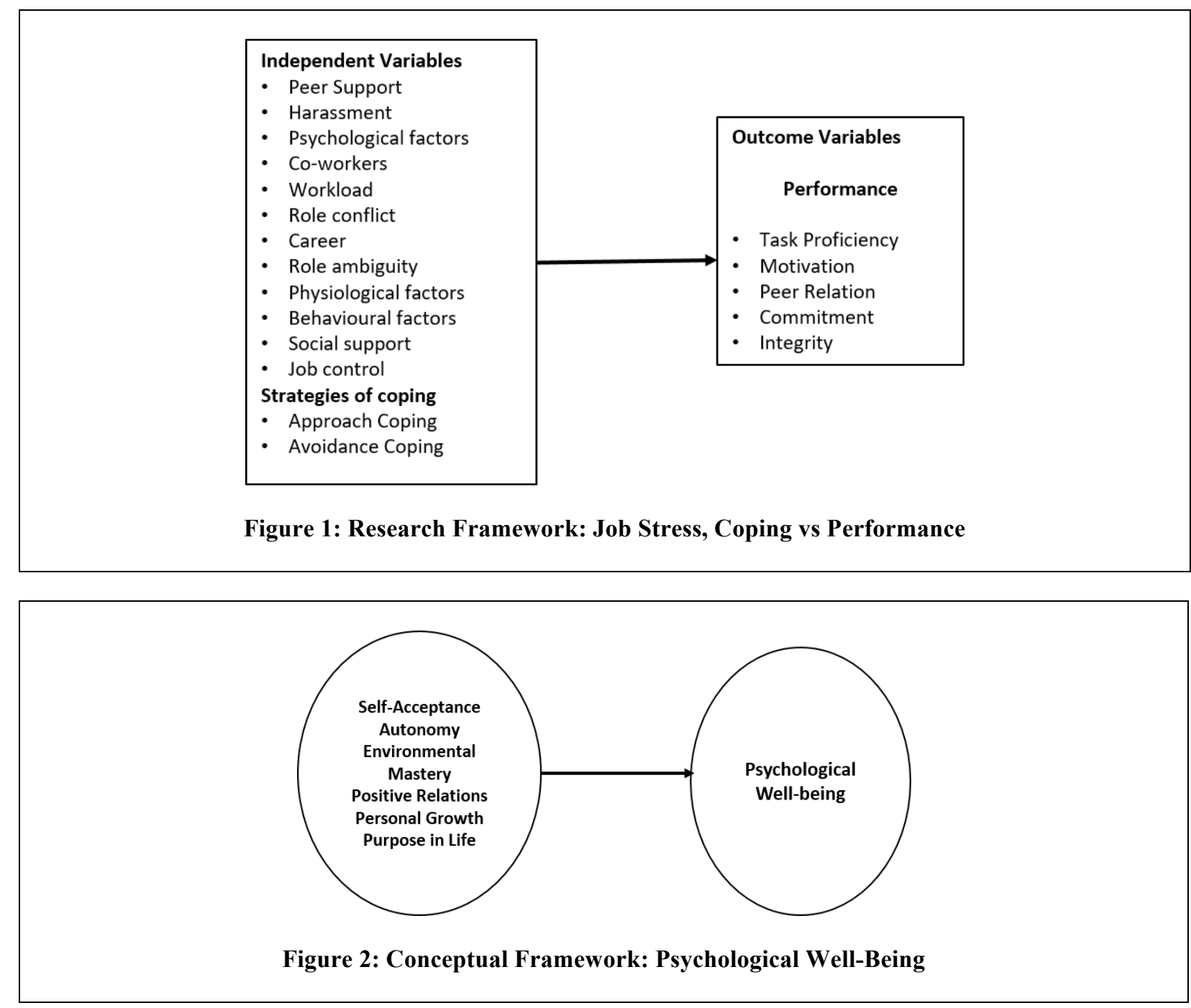

Sample Size: The population of ARS sector is non known thus Cochran (1977) formula was used to determine the representative sample for proportion the estimated sample size is 384 and a sample of 700 was used and details are given in Table 1. 


\begin{tabular}{|l|l|l|}
\hline \multicolumn{2}{|l|}{} \\
\hline Gender & Frequency & Percent \\
\hline Female & 360 & 51.42 \\
\hline Male & 340 & 48.58 \\
\hline Total & 700 & 100 \\
\hline
\end{tabular}

Table 1: Demographic Characteristics of the Study Sample

\begin{tabular}{|c|c|c|}
\hline Age Group & No of respondents & Percent \\
\hline $20-29$ & 206 & $29.4 \%$ \\
\hline $30-34$ & 245 & $35.0 \%$ \\
\hline $35-39$ & 167 & $23.8 \%$ \\
\hline$>40$ & 82 & $11.8 \%$ \\
\hline & 700 & 100 \\
\hline
\end{tabular}

\section{Table 2: Description of the Sample}

Data gathering and Research Instrument: A questionnaire with Four scales - a) job stress measure based occupational stress index (OSI, AK Srivastava and AP Singh, 1984) with 48 questions and14 factors, measured with a 5-point Likert-type scale measuring Strongly agree (5) to Strongly disagree (1); Performance is measured with modified scale based on Campbell 1990, with20 statements, 5 performance components, a 5-point Likert-type scale with 1(strongly disagree) to 5 (strongly agree). The strategies of coping measure based on the scaled by AK Srivastava (2001) has 20 questions relate to Approach and Avoidance copings with a Likert-type scale with 5 (Almost Always) and 1 (Never). The Physiological Well-Being scale has 24 statements based on modified version of Ryff's measurement. The demographic characteristics sex, age, experience, education, levels of stress, of the employees, strategies of coping, and impact of the stress and coping on performance and physiological well-being of ARS employees information gathered.

\section{Data Analysis and methods of Reliability:}

Reliability methods based on William Trochim, 2006; and Cronbach, 1951, used to determine the internal consistency and reliability of the instrument. Table 2 represents the measures of the reliability statistic Cronbach's alpha. The SPSS ver-25 was used for all the statistical analysis including MLR analysis (IBM SPSS Statistics, 2018). The Cronbach alpha values of Table 3 indicate the strong reliability of the instrument.

\begin{tabular}{|l|l|c|}
\hline S1. No & Factor & Cronbach's alpha \\
\hline & C-alpha value for predictor components (1-14) & 0.87 \\
\hline 1 & Work overload & 0.80 \\
\hline 2 & Co-workers & 0.71 \\
\hline 3 & Peer support & 0.72 \\
\hline 4 & Role Ambiguity & 0.79 \\
\hline 5 & Role Conflict & 0.70 \\
\hline 6 & Career & 0.78 \\
\hline 7 & Harassment & 0.73 \\
\hline 8 & Physiological factors & 0.72 \\
\hline 9 & Psychological factors & 0.72 \\
\hline 10 & Behavioural factors & 0.78 \\
\hline 11 & Social support & 0.76 \\
\hline 12 & Job control & 0.80 \\
\hline 13 & Approach coping & 0.76 \\
\hline 14 & Avoidance coping & 0.80 \\
\hline 15 & Performance & 0.69 \\
\hline 16 & Psychologial well-being & 0.78 \\
\hline Source: Primary Data & \\
\hline
\end{tabular}

Table 3: Reliability Statistic C-Alpha Values for Study Factors

The mean value, overall is 3.12 and SD was 0.35 . Using these values job stress score for Low, Medium and High levels of stress determined (Table 4). Andre Francis 2008 and Sumathi and Nandagopal 2015, method was followed to determine the level measurements. The standard deviation is added to the Mean, and resultant values is the higher 
level stress. The difference between mean and standard deviations is low level of job stress. The level between minimum and maximum is moderate job stress level (Prasad et al. 2016,2017, Sumathi and Nandagopal, 2015).

\begin{tabular}{|l|l|}
\hline Scores Measurement & Influence Level \\
\hline$(\mathrm{X}+\sigma)=3.12+0.35=3.47(>3.47)$ & High \\
\hline$(\mathrm{X}-\sigma)=3.12-0.35=2.77(<2)$. & Low \\
\hline 2.77 to 3.47 & Moderate \\
\hline
\end{tabular}

\section{Results}

Table 4: Levels of Job Stress Scores

To examine the effect of job stress, approach and avoidance coping, effect. Performance and Psychological wellbeing, MLR analysis was run. The effect on performance and psychological well-being caused by the job stress factors and coping were categorized into to 3-levels Low, Moderate and High effects. Therefore, the outcome variable is categorical with more than 2 categories and in SPSS the variables were stored as nominal variables.

To measure the independent variables effect on performance and psychological well-being on unordered classifications low, moderate and high effect groups, a multinomial logistic regression was carried out. The High effect is the reference category for the outcome variables and 2other categories, Low and Moderate effects were compared with High Effect category. At first instance, the Low effect is the first column of Table 6 (in terms of performance effect), was compared with High effect. From the odd ratio results, it is established that job stress has significant effect on performance $(\mathrm{OR}=7.0705)$. The relative $\log$ odd ration $(\operatorname{Exp}(ß))$ it can be noted that the measure is for each predictor variable, the outcome variables for each alternative category is measured, however, not for the reference category. Considering the parameter estimates Table 6 , the comparison is made with low effect (first half) with High effect. The second half will be compared moderate effect of with High effect in terms of performance. For this model, low effect comparing with high effect, for each unit increase of job stress, the odds of decreasing performance in low effect group is 7.0705 times $(95 \%$, CI 3.246-15.425, $\mathrm{p}<0.001)$ keeping the other parameters of the model constant; similarly, for each unit increase on approach coping the likely odds of increase in performance is 2.397 times $(95 \%$, CI0.4521-13.658) and so on. There was no significant influence of coping strategies followed on performance and gender. However, there is statistically significant influence of age on performance. No significant gender and age difference were observed on job stress effect on performance.

In the similar way the other comparison with moderate effect versus high effect and being male, the effect of performance in moderate effect group is 0.502 times $(95 \%$, CI $0.239-1.054, p<0.001)$. The job stress and age are also predictors of psychological well-being in the ARS (Table 7). When comparing approach coping with moderate effect versus high effect and the psychological well-being effect in moderate effect group is 0.804 times $(95 \%$, CI 0.073-8.829 $\mathrm{p}<0.001)$ and so on. Avoidance coping and approach are weak predictors of psychological well-being. Most of the odd rations are $>0.2$ indicating significant effect of the model

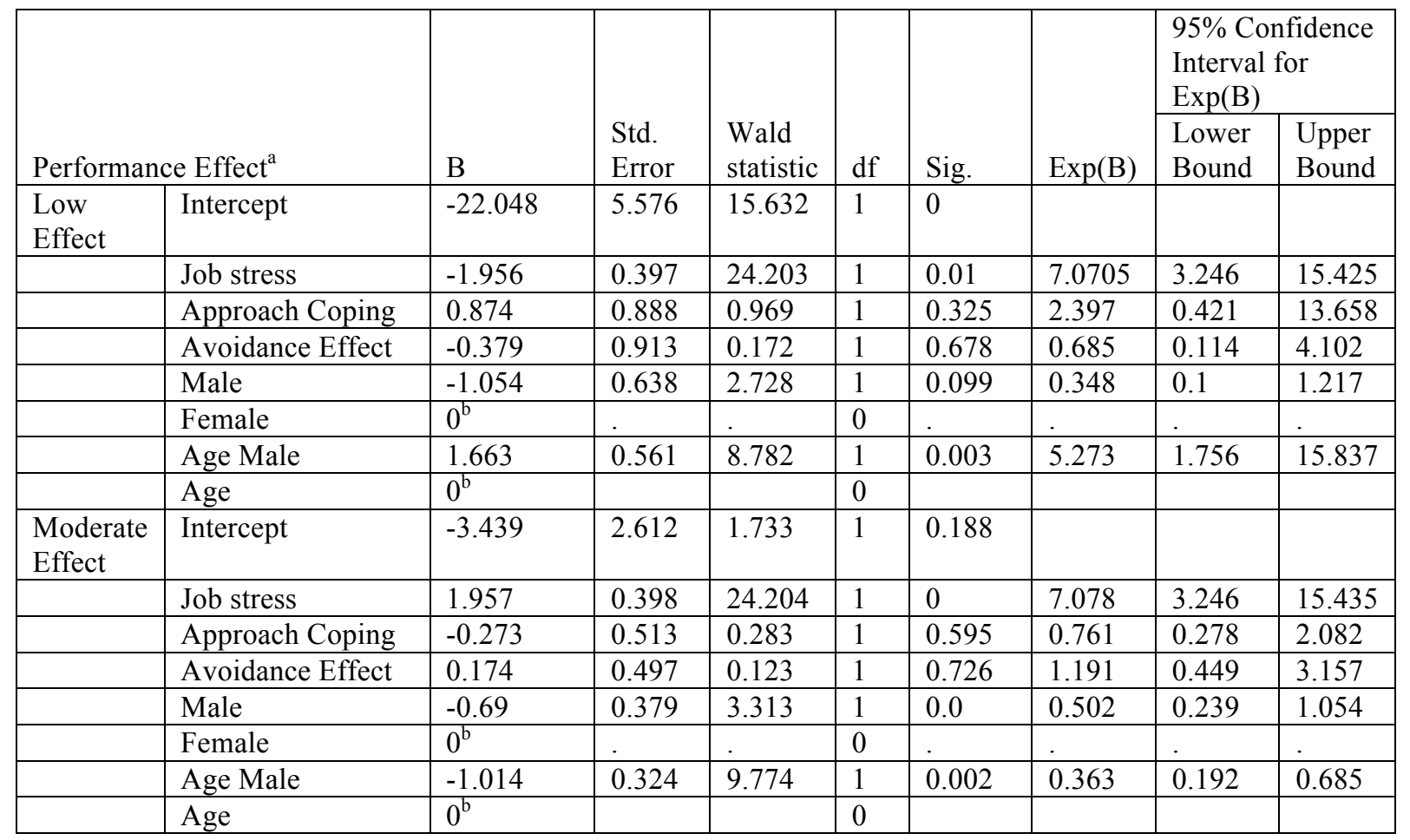


\begin{tabular}{|l|}
\hline a. High Effect is reference category. \\
\hline b. the redundant parameters were set to zero.
\end{tabular}

Table 6: Estimated Probabilities from MLS Analysis on Influence of Job Stress, Coping Strategies (Approach and Avoidance Coping) on Performance of ARS Employees

From the parameter estimates it can be concluded that job stress is statistically significantly influencing the performance and psychological well-being of the ARS employees. However, both the coping strategies avoidance and approach are significantly influencing the outcome variables. Therefore we partially accept the alternate hypothesis $\mathbf{H}_{11}$ :Performance of ARS Employees is related to Job stress and coping.

The parameter estimates establish statistically significant differences with the age and gender effect performance and psychological well-being of ARS employees therefore we reject the null hypothesis and accept the alternative hypothesis $\mathbf{H}_{12}$ :The age and gender differences are statistically significant with psychological well-being of ARS Employees

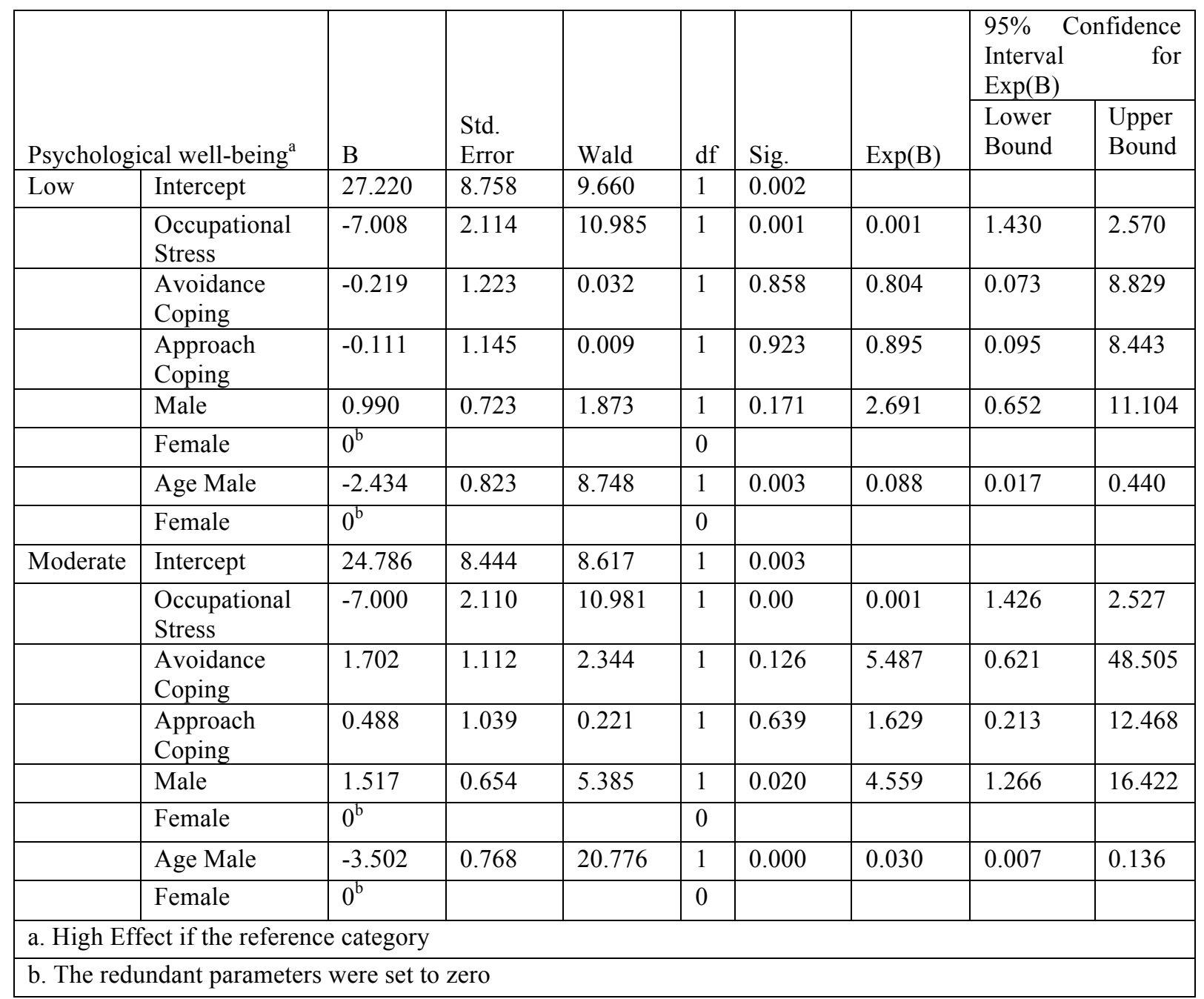

Table 7: Predicted Probabilities from MLS Analysis on Influence of Job Stress, Coping Strategies (Approach and Avoidance Coping) on Psychological Well-being of ARS Employees

\section{Discussion and Conclusions}

The results are in line with the Supran Kumar Sharma, Jyoti Sharma, and Arti Devi (2012), Kumar, K.S. and Madhu(2012), (Prasad et. al. 2016), Waghachavare, V. B., et. al. (2013), Zoeckler, Jeanette M (2017) and Ning Li et al. (2018). Survey studies always have reliability issues and misunderstanding of the statements. However, with the $\mathrm{C}$-alpha statistics indicate with sound internal consistency, the reliability problems were mitigated. The staff at the agricultural research sector perceive moderate job stress that effects the psychological well-being and performance. Flexi working time, improving peer relations, peer support, family support will mitigate the stress. The organization should be responsible for having stress mitigating efforts such as meditation, yoga and exercises, social gatherings to improve the psychological well-being of employees. 


\section{References}

1. Andre Francis. 2008\. Business Mathematics and Statistics. 6th Edition. South Western Cengage Learning EMEA, High Holborn House. 50-51 Bedford Row, London WC1R 4LR. ISBN 978-1-84480-128-2.

2. Burns KL. Perceived Organizational Support and Perceived Supervisor Support as Antecedents of Work Engagement, 1-57, 2006

3. Campbell CH, Ford P, Rumsey MG, Pulakos ED. Development of multiple job performance measures in a representative sample of jobs, Personnel Psychology, 43: 277-300 1990.

4. Cochran, WG.Sampling Techniques: 3d Ed. New York: Wiley, 1977

5. Cooper CL, Marshall J. Sources of managerial and white collar stress, IN. 1978

6. Cronbach L. Coefficient Alpha and Internal Structure of Tests. Psychometrika 16, 297-334, 1951

7. Kahn RL, Wolfe DM, Quinn RP, Snoek JD, Rosenthal, RA. Organizational Stress: Studies in Role Conflict and Ambiguity. New York: Wiley, 1964

8. MasoudLotfizadeh, Maimaiti N, Ismail NH. 2014 Occupational stress among white collar employees in Esfahan Steel Company, Iran. Malaysian Journal of Public Health Medicine 14(1) 79-81, 2014

9. Oluwole A. Odetunmibi (2017). An Investigation of Dynamic Influence to Doctors' Stress in Government Hospitals in Nigeria Using Logistic Regression Approach. Pages`1-6 in Proceedings of the World Congress on Engineering and Computer Science 2017 Vol I WCECS 2017, October 25-27, 2017, San Francisco, US

10. Prasad KDV, Vaidya R, Anil Kumar V. A Study on Causes of Stress among the Employees and Its Effect on the Employee Performance at the Workplace in an International Agricultural Research Institute, Hyderabad, Telangana, India. International Journal of Management Research and Business Strategy, 4, 6882,2015

11. Prasad KDV, Vaidya R, Anil Kumar V. 2018. Association among Occupational Stress factors and Performance at workplace among Agricultural Research Sector Employees at Hyderabad, India. Pacific Business Review International 10(7):27-36, 2018

12. Ryff CD. Happiness is everything, or is it? Explorations on the meaning of psychological wellbeing. Journal of personality and social psychology, 57(6), 1069, 1989

13. Sateesh Kumar K, Madhu G. Analysis and multinomial logistic regression modelling work stress in manufacturing industries in Kerala, India. International Journal of Advances in Engineering \& Technology 2(1): 410-418. 2012

14. Selye H. Stress in health and disease Butterworth's, Inc. Boston, MA, 1976

15. Selye H. The general adaptation syndrome and the diseases of adaptation. Journal of Clinical Endocrinology. 2: 117-230, 1956

16. Sharma SK, Sharma J, Devi A. Determinants of role stress based on employee segmentation: a multinomial logit analysis. Management: journal of contemporary management issues, 17(2), 1-30, 2012

17. Srivastava AK, Singh AP. The occupational stress index, ManavaigyanicParikshanSansthan, Varanasi, 1984

18. Srivastava, AK., Coping Strategy Scale, (2001), Rupa Psychological Centre, Varanasi.

19. Stephen EB. Occupational stress and coping strategies among female employee of commercial banks in Nigeria. International Journal of Scientific Research and Management 2(9):1417-1430, 1984

20. Sumathi Annamaliand Nandagopal, R. . Occupational Stress: A study of Employee Stress in Indian ITES Industry. Pp 165. Allied Publishers Pvt. Ltd. India, 2015

21. Suryawanshi A, Savasani M and Shah J A study of stress level of married men and women using multinomial logistic regression. International Journal of Scientific Research Publications. 5(8): 1-8, 2015

22. William Trochim KM. Types of reliability. Research Methods Knowledge Base. Web Center for Social Research Methods. http://www.socialresearchmethods.net/kb/reltypes.php. 2006 